\title{
A estrutura das representações sociais sobre saúde e doença entre membros de movimentos sociais
}

\author{
The structure of social representations on health and illness \\ among members of social movements
}

Helena Eri Shimizu ${ }^{1}$

Jessica Reis e Silva ${ }^{2}$

Luciana Melo de Moura ${ }^{3}$

Ximena Pamela Días Bermúdez ${ }^{1}$

Muna Muhammad Odeh ${ }^{1}$

${ }^{1}$ Departamento de Saúde Coletiva, Programa de Pós-Graduação em Saúde Coletiva, Faculdade de Ciências da Saúde, Universidade de Brasília. Campus Universitário Darcy Ribeiro, Cidade Universitária. 70910900 Brasília DF Brazil. shimizu@unb.br

${ }^{2}$ Faculdade de Medicina, Universidade de Brasília. ${ }^{3}$ Secretaria de Estado de Saúde do Distrito Federal.
Abstract The scope of the study was to identify the structure of social representations regarding health and illness as expressed by representatives of social movements. The study included $66 \mathrm{mem}$ bers of social movements in the Federal District of Brazil. A questionnaire was applied to obtain the socio-economic profile of the participants and the free association technique was used in order to identify the likely peripheral and central core of the social representations analyzed by version 2000 EVOC software (Ensemble de Programmes Permettant l'Analyse des Évocations). The study results indicate that the majority of the participants have been activists for longer than six years, male, young adults, with above high school level education, monthly income over two minimum salaries, and are users of the Brazilian Unified Health System. Concerning the social representations of health structure, it was found that "quality of life" comprised the core system, while in the case of the social representations of illness, the core was found to be "suffering." The study suggests that the respondents' social representations of health and illness remain distant from a Social Determinants paradigm considered necessary for the assertion of the right to health and for achieving quality of life.

Key words Health, Illness, Social representation, Social movements
Resumo Este estudo buscou analisar as representações sociais de saúde e doença dos integrantes dos movimentos sociais da saúde do Distrito Federal, a fim de destacar potencialidades e limitações à ampliação da garantia da integralidade da atenção à saúde. Aplicou-se questionário a 66 participantes para verificar o seu perfil, além do emprego da técnica de associação livre e hierarquização de itens com termo indutor saúde e doença para identificação da estrutura das representações sociais, que foram analisados com o software EVOC (Ensemble de Programmes Permettant l'Analyse des Évocations) versão 2000. Os integrantes dos oito movimentos identificados são majoritariamente adultos jovens, masculinos, militantes há mais de seis anos, que estudaram além do ensino médio, renda acima de dois salários mínimos e usuários do SUS. A estrutura das representações sociais demonstra que o elemento qualidade de vida compõe o núcleo central do termo saúde e o elemento sofrimento do termo doença. As representações sociais do processo saúde-doença indicam avanços na sua concepção, entretanto necessitam ser consubstanciadas na perspectiva do modelo de determinação social. Os movimentos sociais são essenciais para mobilizar a sociedade na definição do padrão de saúde desejável por meio do desenvolvimento de políticas públicas.

Palavras-chave Saúde, Doença, Representação social, Movimentos sociais 


\section{Introdução}

O presente artigo procura apreender a estrutura das representações sociais ${ }^{1}$ de participantes dos movimentos sociais da saúde acerca da saúde e da doença. Como documentado na literatura, durante a construção do Sistema Único de Saúde (SUS), especialmente no processo da Reforma Sanitária, os movimentos sociais foram protagonistas na defesa da democratização da saúde ${ }^{2,3}$. A concepção de saúde era vista por esses movimentos não apenas como um valor em si, mas como um meio para contribuir com a solução dos problemas oriundos das desigualdades sociais vigentes, tanto na perspectiva da melhoria do estado de saúde da população, quanto do acesso mais equitativo aos serviços de saúde ${ }^{2-5}$.

Como resultado desse processo, conquistouse na Constituição de 1988, a saúde como: "direito de todos e dever do Estado”. Na lei n. ${ }^{\circ} 8.080$, de 1990, foi definido como fatores determinantes condicionantes da saúde: a alimentação, a moradia, o saneamento básico, o meio ambiente, o trabalho, a renda, a educação, o transporte, o lazer e o acesso aos bens e serviços essenciais ${ }^{6}$, reconhecendo os determinantes sociais de saúde e uma dimensão mais compreensiva do significado da saúde.

O conceito de movimentos sociais vem sendo amplamente debatido na literatura sociológica. Na perspectiva de Tourraine ${ }^{7}$, eles estão no cerne da sociedade industrial e envolvem ações coletivas que põem em xeque formas específicas de dominação. Eles são produzidos em contextos históricos característicos, afetando o conjunto da vida social. Porém, com as transformações do século XX e o advento da globalização, as relações sociais foram sendo modificadas, e hoje, se questiona a pertinência de utilização da categoria movimentos sociais, dando lugar a denominações conceituais como movimentos históricos ou movimentos culturais em dependência do tipo de tensão que geram no tecido social. Contudo, o próprio Tourraine ${ }^{7}$ considera que ainda é pertinente falar de movimentos sociais nas sociedades contemporâneas, ao constatar que persistem as lutas por conquistas e espaços sociais.

Sem pretender aqui adentrar na história da reforma sanitária no Brasil, cabe reconhecer no conjunto de forças sociais organizadas nos finais da década de 80, aglutinadas ao redor desse objetivo político que era a democratização da saúde e a renovação do papel do estado, indícios de um movimento social na perspectiva proposta por Tourraine ${ }^{7}$.
Os movimentos sociais podem também ser entendidos como uma rede que pressupõe a identificação de sujeitos coletivos em torno de valores, objetivos ou projetos em comum, os quais definem os atores ou situações sistêmicas antagônicas que devem ser combatidas e transformadas ${ }^{8,9}$. Torraine explica ainda que os movimentos sociais que tendem a se tornar movimentos culturais diferem dos tradicionais porque ultrapassam o quadro do político para assimilar uma organização sistêmica, sobretudo por meio do uso das redes de comunicação ${ }^{7}$, para se articular entre si e com os outros movimentos a fim de ganhar visibilidade, produzir impacto na esfera pública e obter conquistas para a cidadania ${ }^{8,10}$. Possivelmente os novos movimentos sociais da saúde têm assimilado essas características, sobretudo porque o acesso à saúde integral é ainda um direito a ser conquistado.

A identidade de um movimento social surge a partir de suas necessidades e seus desejos. Já a sua identidade política é reconhecida no processo de luta perante a sociedade civil e política, e o seu reconhecimento jurídico (construção formal de um direito) serão legítimos caso constituam uma resposta do Estado à demanda organizada ${ }^{8,9,11}$. Deste modo, a identidade de um movimento vem do reconhecimento da institucionalidade da ação, e não deriva de um processo de institucionalização da ação coletiva ${ }^{8,9,11}$, como comumente tem sido observado nas políticas públicas do Brasil.

Nas últimas décadas, ocorreram transformações na configuração dos movimentos sociais, que não se limitaram à política, à religião, às demandas socioeconômicas e trabalhistas, mas também se dedicaram às questões identitárias e culturais $^{8,9,11}$, temas que antes ficavam restritos à esfera privada.

Além dessas questões, continuam compartilhando as lutas pela terra, pela distribuição de renda, pela igualdade entre as nações "antiglobalização". Portanto, nenhum ator social contemporâneo luta sozinho, mas atua em rede, numa articulação que é global e cuja ação é local ${ }^{8,9,11}$.

Observa-se que na luta por direitos e construção de identidades, esses novos movimentos conquistaram progressivo suporte governamental via implementação das políticas públicas. E, na atualidade, não se podem esquecer que as inúmeras ações e redes cidadãs traduzem expressões desses movimentos em ações de fiscalização e controle das políticas públicas, atuando em fóruns, conselhos, câmaras, consórcios, em escala local, regional e nacional ${ }^{11-13}$. 
Em junho de 2013, o Brasil foi surpreendido com a tomada das ruas por diversos movimentos sociais que reivindicaram melhorias dos serviços públicos, dentre esses, o acesso aos serviços de saúde de qualidade e maior transparência na política. Embora não seja foco deste estudo analisar os protestos ocorridos nesse período, há que se considerar que essa inusitada participação da sociedade civil em demanda de democratização da gestão da coisa pública, injetou novo fôlego à luta pelas desigualdades do país, pontuando a inversão das prioridades da gestão, no sentido de abarcar políticas que atendam não apenas questões emergenciais, a partir do espólio de recursos insuficientes destinados às áreas sociais, mas trouxeram ao debate assuntos que afetam a estrutura social e a própria constituição da sociedade $e^{3,11-13}$.

Neste sentido, os manifestantes de 2013, em seus variados matizes de práticas, ideologias e pertencimentos, possivelmente estimularam os movimentos sociais em saúde a trazerem de volta a possibilidade da utopia, nos moldes libertários, com foco no ser humano e suas necessidades, dentre as quais se destaca os serviços públicos de saúde com qualidade e o combate às desigualdades sociais.

Desta feita, tais mobilizações instigam a necessidade de aprofundar as reflexões sobre a importância dos movimentos sociais da saúde, que com o passar do tempo se modificaram, porque cresceram ao incorporar novos atores, e desenvolveram novos arranjos de participação social, sobretudo de forma institucionalizada, que imprimiram mudanças positivas, mas também concorreram, em certa medida para a preservação da estrutura social desigual e fortemente hierarquizada, que tem dificultado a defesa de uma proposta universalista e igualitária em saúde ${ }^{10}$. Ademais, é preciso reconhecer que se encontram mais fragmentados devido ao fenômeno denominado globalização que deslocaram os espaços e mecanismos de conflitos sociais.

Fica evidente, portanto, que é preciso resgatar a dinamicidade dos movimentos sociais da saúde com a finalidade de destacar as demandas materiais, que têm como referência objetiva as exclusões e carências cotidianas, que devem ser traduzidas em representações simbólicas, que são essenciais para fortalecer a defesa da saúde ${ }^{8}$. Neste sentido, prescinde-se do ponto de vista dos atores que são conhecedores do que têm em comum, ou seja, dos mecanismos de conflitos e interesses particulares ${ }^{7}$.

Com base no exposto, interessa, neste estudo, conhecer as representações de saúde e da doen- ça de sujeitos membros desses movimentos, pois parte-se do pressuposto que as representações positivas da saúde podem ser profícuas para consubstanciar as lutas pela garantia da integralidade da atenção à saúde.

Nesta perspectiva, entende-se que em uma sociedade pensante, seus indivíduos não são apenas portadores de ideias e crenças coletivas, mas pensadores ativos, que mediante processo de interação social, produzem e comunicam suas próprias representações e soluções para as questões que se colocam a si mesmos ${ }^{14,15}$.

\section{Objetivo geral}

Analisar as representações sociais acerca da saúde e doença dos integrantes dos movimentos sociais da saúde do Distrito Federal, a fim de destacar suas potencialidades e limitações à ampliação da garantia da integralidade da atenção à saúde.

\section{Objetivos específicos}

- Caracterizar o perfil sociodemográfico de participantes dos movimentos sociais da saúde do Distrito Federal;

- Identificar a estrutura - núcleo central e sistemas periféricos - das representações sociais acerca da saúde e da doença entre esses participantes;

- Refletir sobre as potencialidades e limitações dos movimentos sociais da saúde para contribuir com ampliação da garantia do direito à saúde preconizada pelo Sistema Único de Saúde.

\section{As representações sociais}

As representações sociais são mensagens mediadas pela linguagem, construídas socialmente e, necessariamente, ancoradas no âmbito do contexto do indivíduo que as emite ${ }^{15}$. São, portanto, conhecimentos específicos a um dado conjunto social. Segundo Serge Moscovici, formam-se a partir de observações e de suas análises, da influência das ciências e das filosofias ${ }^{14}$. Mais precisamente, surgem da continuidade entre o universo exterior e o indivíduo a partir das inter-relações individual/coletivo ${ }^{14,15}$. Resultam do poder inerente ao ser humano de criar objetos, acontecimentos e atitudes representativas; da relação entre nosso "repositório" de imagens e da capacidade de manifestá-las nas diversas expressões humanas.

Enquanto se cria a representação de um objeto, também o sujeito se constitui, ao se situar no universo social e material segundo sua orga- 
nização do real. Quando o sujeito expressa uma opinião sobre um objeto, supõe-se a contribuição para a elaboração de uma representação ${ }^{15}$. Entende-se que as representações sociais são conjuntos dinâmicos, sua característica é a produção de comportamentos e de relações com o meio. É uma ação que modifica a ambos, e não uma reprodução destes comportamentos ou destas relações, nem uma reação a um estímulo exterior dado $^{15,16}$

E ainda é possível considerar uma representação social como uma "preparação para a ação", no sentido de que orienta o comportamento e, principalmente, recria o meio em que ele acontece ${ }^{1}$. É capaz de conferir sentido ao comportamento, integrando-o em uma rede de relações com seu objeto e proporcionando noções que tornam estáveis e eficazes essas relações ${ }^{1,14-16}$. Por isso, as representações sociais podem ser consideradas como importantes referências da prática cotidiana.

$\mathrm{Na}$ perspectiva estruturalista das representações sociais os estudos de Jean-Claude Abric ${ }^{1}$ procuram resolver aparentes contradições no desmembramento das representações sociais em núcleo central e sistema periférico. Celso Pereira de Sá argumenta que as representações são ao mesmo tempo estáveis e móveis, rígidas e flexíveis; e as representações são consensuais, mas também marcadas por fortes diferenças interindividuais ${ }^{17}$. Para este último, essas aparentes contradições se originam das características estruturais das representações sociais e de seu modo de funcionamento.

Haveria assim, em primeiro lugar, um "sistema central" constituído pelo núcleo central da representação, ao qual são atribuídas as seguintes características: é marcado pela memória coletiva, refletindo as condições históricas, sociológicas e ideológicas do grupo; constitui base comum, consensual coletivamente partilhada das representações, propiciando homogeneidade do grupo social; é estável, coerente, resistente à mudança, assegurando assim a continuidade e a consistência da representação; e é relativamente pouco sensível ao contexto social e material imediato no qual a representação se manifesta ${ }^{17,18}$. Outorga significado básico da representação e determina a organização de todos os elementos.

Em segundo lugar haveria um "sistema periférico" constituído pelos demais elementos da representação, que, provendo a interface entre a realidade concreta e o sistema central, atualiza e contextualiza as determinações normativas e consensuais deste último, daí resultando a mo- bilidade, a flexibilidade e a expressão individualizada das representações sociais ${ }^{17,18}$. O sistema periférico, por sua vez, permite a integração das experiências e histórias individuais; suporta a heterogeneidade do grupo, as contradições e é evolutivo e sensível ao contexto imediato.

Sintetizando, suas funções consistem, em termos cotidianos, na adaptação à realidade concreta e na diferenciação do conteúdo da representação e, em termos históricos, na proteção do sistema central.

Aplicada ao campo da saúde ${ }^{5,19}$, a teoria das representações sociais elucida os sentidos atribuídos à saúde, à doença na vida cotidiana e à forma em que contextos socioculturais e históricos articulam ideias e ações no que concerne a esse processo ${ }^{17,19,20}$. As representações sociais são compostas pelas percepções do sujeito e não são facilmente alteradas por novos conhecimentos, possuindo forte influência do contexto em que são formadas. A partir deste fato é possível antever o quanto de subjetividade existe no modo dos sujeitos verem e representarem, no campo deste trabalho, o processo saúde-doença.

As representações sociais de integrantes de movimentos sociais, enquanto objeto de estudo, requerem ser situadas à luz das características, lutas e histórias desses atores, levando em conta a configuração dos movimentos sociais do Brasil contemporâneo.

\section{Percurso Metodológico}

O estudo foi realizado com participantes dos movimentos sociais da saúde do Distrito Federal (DF), que por ser capital federal agrega diversos movimentos sociais.

Inicialmente, buscou-se identificar os movimentos sociais da saúde atuantes no DF, cujos integrantes foram contatados utilizando-se a estratégia de indicação de pares, ou seja, a técnica bola de neve.

Os dados foram coletados por meio de questionário semiestruturado organizado em duas partes. A primeira seção sobre o perfil sociodemográfico dos sujeitos registrou as variáveis de sexo, faixa etária, grau de escolaridade, renda média mensal, se era usuário do Sistema Único de Saúde (SUS) e se possuía plano de saúde. Também incluiu aspectos para traçar o perfil de envolvimento do sujeito com o movimento social elencando variáveis relativas ao nível de participação no movimento social (liderança ou integrante) e tempo de militância. Foram aplica- 
dos 66 questionários, dos quais 61 foram corretamente preenchidos quanto ao tema saúde, mas cinco deles foram retirados da análise por não terem completado questões relativas à representação social de doença.

A segunda parte do questionário incorporou técnicas de evocação livre e de hierarquização de itens ${ }^{1,17}$, sendo solicitados aos participantes escrever pelo menos três palavras ou expressões que lhe ocorressem, imediatamente, em relação a cada termo indutor "saúde" e "doença". Em seguida, os participantes deveriam enumerar em ordem de importância as palavras ou expressões indicadas.

Os dados foram analisados por meio do software EVOC (Ensemble de Programmes Permettant l'Analyse des Évocations) versão 2000, que permite identificar o "núcleo central" e "sistemas periféricos" das representações sociais.

Para testar a centralidade ${ }^{17}$ dos termos que compõem as representações sociais de saúde e doença, foram calculados os percentuais da "queda de frequência" entre a frequência total dos termos apresentados pela técnica de evocação e os termos hierarquizados como os três mais importantes referidos pelos participantes da pesquisa. Esse indicador forneceu mais elementos para identificação da estrutura das representações. Neste estudo, considerou-se a queda de frequência inferior a $10 \%$ como indicador de centralidade do termo, segundo a seguinte fórmula:

Queda de frequência $(\%)=\frac{\mathrm{Ft}-\mathrm{Fp}}{\mathrm{Ft}} \times 100$

Sendo Ft a frequência de todos os termos evocados e processados pelo EVOC e Fp a frequência dos termos que, dentre os evocados, foram considerados pelos participantes como os três mais importantes. Foram considerados apenas termos com frequência de evocação $\geq 5$.

A pesquisa observou os critérios éticos aplicáveis em seres humanos, tendo sido aprovada pelo Comitê de Ética em Pesquisa da Secretaria de Estado de Saúde do Distrito Federal (SES-DF), e os sujeitos da pesquisa assinaram e dataram o termo de consentimento livre e esclarecido.

\section{Resultados}

A sistematização dos dados (Tabela 1) demonstra que foram identificados oito movimentos sociais da saúde no Distrito Federal, não excluindo a possibilidade de existirem outros no território. É possível inferir que todos os movimentos estu- dados assimilam a ideia dos novos movimentos sociais, e que a maioria dos movimentos estudados relaciona-se com as questões de gênero como o Movimento Nacional das Cidadãs Positivas do DF, Combate à Homofobia, Promotoras Legais Populares, Grupo Estruturação, Coturno de Vênus e Fórum de Mulheres do Distrito Federal e Entorno.

Quanto ao perfil sociodemográfico (Tabela 1) dos integrantes dos movimentos sociais da saúde verificou-se predomínio de participantes do sexo masculino $(68,2 \%)$, jovens $(37,9 \%)$, com grau de escolaridade de nível médio ou acima $(75,8 \%)$ e renda salarial acima de dois salários mínimos (51,5\%). Sobre o acesso aos serviços de saúde, a maioria relatou não possuir plano de saúde $(69,7 \%)$ e ser usuária do SUS (71,2\%). Quanto às características de participação nos movimentos sociais, em sua maioria se reconhecem como membros $(59,1 \%)$.

No que se refere à estrutura das representações sociais, a análise referente ao tema saúde encontra o termo "qualidade de vida" no primeiro quadrante (Tabela 2), possivelmente compondo o núcleo central da representação. No segundo quadrante estão os termos que provavelmente fazem parte do sistema periférico mais próximo do núcleo central. A saúde é relacionada com o "bem-estar" do sujeito e acredita-se que seja influenciada pela "alimentação". É entendida como um "direito" e, portanto, todos devem ter acesso à "saúde pública”. Observa-se também a importância dada à "prevenção", aos cuidados do "médico", ao "atendimento" recebido e à necessidade de "paz" para obter a saúde necessária à atuação na "vida".

No "sistema periférico" mais distante, a saúde é representada como o resultado da vivência do "amor" e da "alegria". Mas os cuidados recebidos em um "hospital" e o tratamento por meio do uso de "remédios" também são relevantes para restabelecer a saúde e garantir a capacidade de exercer o "trabalho".

$\mathrm{Na}$ análise da estrutura da representação social do tema doença, o núcleo central encontrado foi "sofrimento", já que integra o primeiro quadrante (Tabela 3).

No segundo quadrante, o qual corresponde ao sistema periférico próximo das representações sociais da doença, nota-se a relação com a "má alimentação", e as ideias de sentir "dor", aproximar-se da "morte" e viver momento de "tristeza". Pode ser entendida como resultado da negligência com a "prevenção" da saúde. Além disso, a doença criaria a necessidade de "cuidado" com o enfermo, principalmente em um "hospital". 
Tabela 1. Caracterização dos integrantes dos movimentos sociais. Distrito Federal, 2014.

\begin{tabular}{|c|c|c|}
\hline Variáveis & $\mathbf{N}$ & $\%$ \\
\hline \multicolumn{3}{|l|}{ Movimentos sociais } \\
\hline Rádio Web Saúde - Qualidade, comunicação e informação sobre o SUS. & 10 & 15,15 \\
\hline Projeto Vidas Paralelas Indígena - Saúde indígena. & 8 & 12,12 \\
\hline $\begin{array}{l}\text { Movimento Nacional das Cidadãs Positivas do DF - reintegração familiar e social; } \\
\text { fortalecimento das mulheres soropositivas. }\end{array}$ & 3 & 4,55 \\
\hline $\begin{array}{l}\text { Combate à Homofobia - Construção e execução de um programa antissexista, anti-homo/ } \\
\text { transfóbico, antirracista. }\end{array}$ & 10 & 15,15 \\
\hline Promotoras Legais Populares - Igualdade de gênero, social, étnica. & 5 & 7,58 \\
\hline Grupo Estruturação - Direitos humanos voltados aos/às LGBT, melhoria na qualidade de vida. & 17 & 25,75 \\
\hline Coturno de Vênus - direitos sexuais e reprodutivos, descriminalização do aborto. & 5 & 7,58 \\
\hline $\begin{array}{l}\text { Fórum de Mulheres do Distrito Federal e Entorno - combate à violência contra as mulheres; } \\
\text { saúde das mulheres; legalização do aborto; monitoramento das políticas às mulheres. }\end{array}$ & 8 & 12,12 \\
\hline \multicolumn{3}{|l|}{ Nível de participação no Movimento social } \\
\hline Liderança & 27 & 40,9 \\
\hline Membro & 39 & 59,1 \\
\hline \multicolumn{3}{|l|}{ Sexo } \\
\hline Masculino & 45 & 68,2 \\
\hline Feminino & 21 & 31,8 \\
\hline \multicolumn{3}{|l|}{ Faixa Etária } \\
\hline 17 a 29 & 25 & 37,9 \\
\hline 30 a 39 & 9 & 13,6 \\
\hline 40 a 49 & 16 & 24,3 \\
\hline 50 a 59 & 10 & 15,2 \\
\hline 60 ou mais & 3 & 4,5 \\
\hline \multicolumn{3}{|l|}{ Escolaridade } \\
\hline $1^{\circ}$ grau incompleto & 14 & 21,2 \\
\hline $1^{\circ}$ grau completo & 1 & 1,5 \\
\hline $2^{\circ}$ grau incompleto & 1 & 1,5 \\
\hline $2^{\circ}$ grau completo & 12 & 18,2 \\
\hline Superior incompleto & 14 & 21,2 \\
\hline Superior completo & 10 & 25,2 \\
\hline Pós-graduação & 14 & 21,2 \\
\hline \multicolumn{3}{|l|}{ Renda Mensal*(salário mínimo) } \\
\hline$<1$ & 9 & 13,6 \\
\hline$\geq 1<2$ & 18 & 27,3 \\
\hline$\geq 2<3$ & 5 & 7,6 \\
\hline$\geq 3<4$ & 2 & 3,0 \\
\hline$\geq 4<5$ & 12 & 18,2 \\
\hline$\geq 5$ & 15 & 22,7 \\
\hline \multicolumn{3}{|l|}{ Usuário do SUS } \\
\hline Não & 15 & 28,8 \\
\hline Sim & 47 & 71,2 \\
\hline \multicolumn{3}{|l|}{ Tempo de militância no Movimento (anos) } \\
\hline$<2$ & 13 & 19,7 \\
\hline $2-5$ & 23 & 34,8 \\
\hline $6-10$ & 27 & 40,9 \\
\hline$>11$ & 3 & 4,5 \\
\hline
\end{tabular}

${ }^{*}$ Dados ausentes (faixa etária $\mathrm{n}=63$ e Renda Mensal $\mathrm{n}=61$ ).

No sistema periférico distante, a doença é relacionada com um "mal-estar", podendo resultar do "estresse" cotidiano ou até mesmo associado às doenças de impacto na subjetividade dos sujeitos, como o "câncer". Menciona-se também neste quadrante, a necessidade de buscar a "cura" da enfermidade, submetendo-se a tratamento com "médico" e utilização de "remédio".

A partir do "teste de centralidade" (Tabela 4) foi possível notar que o termo "qualidade de 
Tabela 2. Tabela de quatro casas com frequência e Ordem Média de Evocação dos termos (OME) relacionados à saúde. Distrito Federal, 2014.

\begin{tabular}{|c|c|c|c|c|c|}
\hline \multicolumn{3}{|c|}{ Núcleo Central ( $1^{\circ}$ quadrante) } & \multicolumn{3}{|c|}{ Sistema Periférico Próximo ( $2^{\circ}$ quadrante) } \\
\hline Evocação & Frequência & OME & Evocação & Frequência & OME \\
\hline & $\geq 7$ & $<1,9$ & & $\geq 7$ & $\geq 1,9$ \\
\hline \multirow[t]{10}{*}{ Qualidade de vida } & 7 & 1,714 & Alimentação & 11 & 3,182 \\
\hline & & & Atendimento & 7 & 2,857 \\
\hline & & & Bem estar & 17 & 2,941 \\
\hline & & & Direito & 10 & 2,000 \\
\hline & & & Médico & 8 & 3,125 \\
\hline & & & $\mathrm{Paz}$ & 7 & 3,286 \\
\hline & & & Política publica & 7 & 4,286 \\
\hline & & & Prevenção & 9 & 2,444 \\
\hline & & & Saúde pública & 11 & 2,545 \\
\hline & & & Vida & 10 & 2,100 \\
\hline \multicolumn{3}{|c|}{ Sistema Periférico Próximo ( $3^{\circ}$ quadrante) } & \multicolumn{3}{|c|}{ Sistema Periférico Distante ( $4^{\circ}$ quadrante) } \\
\hline \multirow[t]{7}{*}{ Evocação } & Frequência & OME & Evocação & Frequência & OME \\
\hline & $\leq 5 \mathrm{e}<6$ & $<1,9$ & & $\leq 5 \mathrm{e}<6$ & $\geq 1,9$ \\
\hline & & & Alegria & 5 & 3,600 \\
\hline & & & Amor & 6 & 3,667 \\
\hline & & & Hospital & 6 & 3,667 \\
\hline & & & Remédio & 5 & 3,800 \\
\hline & & & Trabalho & 5 & 3,200 \\
\hline
\end{tabular}

Tabela 3. Tabela de quatro casas com frequência e Ordem Média de Evocação dos termos (OME) relacionados à doença. Distrito federal, 2014.

\begin{tabular}{|c|c|c|c|c|c|}
\hline \multicolumn{3}{|c|}{ Núcleo Central ( $1^{\circ}$ quadrante $)$} & \multicolumn{3}{|c|}{ Sistema Periférico Próximo ( $2^{\circ}$ quadrante $)$} \\
\hline Evocação & Frequência & OME & Evocação & Frequência & OME \\
\hline & $\geq 7$ & $<1,9$ & & $\geq 7$ & $\geq 1,9$ \\
\hline \multirow[t]{7}{*}{ Sofrimento } & 9 & 1,667 & Alimentação & 10 & 2,800 \\
\hline & & & Cuidado & 8 & 2,750 \\
\hline & & & Dor & 12 & 2,583 \\
\hline & & & Hospital & 8 & 2,500 \\
\hline & & & Morte & 10 & 3,200 \\
\hline & & & Prevenção & 7 & 2,714 \\
\hline & & & Tristeza & 9 & 3,778 \\
\hline \multicolumn{3}{|c|}{ Sistema Periférico Próximo ( $3^{\circ}$ quadrante $)$} & \multicolumn{3}{|c|}{ Sistema Periférico Distante ( $4^{\circ}$ quadrante) } \\
\hline \multirow[t]{8}{*}{ Evocação } & Frequência & OME & Evocação & Frequência & OME \\
\hline & $\leq 5 \mathrm{e}<6$ & $<1,9$ & & $\leq 5 \mathrm{e}<6$ & $\geq 1,9$ \\
\hline & & & Cura & 5 & 3,200 \\
\hline & & & Câncer & 6 & 4,000 \\
\hline & & & Estresse & 5 & 3,000 \\
\hline & & & Mal estar & 6 & 4,000 \\
\hline & & & Médico & 5 & 4,000 \\
\hline & & & Remédio & 5 & 2,800 \\
\hline
\end{tabular}

vida", de fato, parece compor o núcleo central das representações sociais acerca da saúde, pois não apresenta queda de frequência de evocação.
Identificou-se no "teste de centralidade" para os termos relacionados à doença (Tabela 5) que "sofrimento" não possui queda de frequência e, 
portanto, constituiria realmente o núcleo central da representação social do tema em questão.

\section{Discussão}

Quanto à caracterização dos movimentos sociais da saúde do DF, verificou-se a presença majoritária dos chamados novos movimentos sociais vol- tados à dimensão das defesas identitárias como sexo, etnia, raça. Além disso, os movimentos ainda trazem questões mais amplas como a saúde indígena, os direitos sexuais e reprodutivos, e protestam contra as diversas formas de opressão e violência.

Observa-se que a maior parte dos sujeitos entrevistados é do sexo masculino, adultos jovens, que estudaram além do ensino médio, com ren-

Tabela 4. Teste de centralidade a partir do cálculo da queda de frequências de evocação relacionada à saúde. Distrito Federal, 2014.

\begin{tabular}{llccc}
\hline evocados & $\begin{array}{c}\text { Termos } \\
\text { de evocação }\end{array}$ & $\begin{array}{c}\text { Frequência das } \\
\text { palavras principais }\end{array}$ & $\begin{array}{c}\text { Queda de } \\
\text { frequência (\%) }\end{array}$ \\
\hline Núcleo central & Qualidade de vida & 7 & 7 & 0 \\
Sistema Periférico & Médico & 7 & 7 & 12,5 \\
& Saúde pública & 11 & 9 & 18,2 \\
& Direito & 10 & 8 & 20 \\
& Vida & 10 & 8 & 20 \\
& Prevenção & 9 & 7 & 22,2 \\
& Amor & 6 & 4 & 33,3 \\
& Hospital & 6 & 4 & 33,3 \\
& Remédio & 5 & 3 & 40 \\
& Trabalho & 5 & 3 & 40 \\
& Bem estar & 17 & 10 & 41,2 \\
& Atendimento & 7 & 4 & 42,9 \\
& Paz & 7 & 4 & 42,9 \\
& Alimentação & 11 & 6 & 45,4 \\
& Política pública & 7 & 3 & 57,1 \\
& Alegria & 5 & 2 & 60 \\
\hline
\end{tabular}

Tabela 5. Teste de centralidade a partir do cálculo da queda de frequências relacionadas à doença. Distrito Federal, 2014.

\begin{tabular}{llccc}
\hline evocados & $\begin{array}{c}\text { Termos } \\
\text { erequência total } \\
\text { de evocação }\end{array}$ & $\begin{array}{c}\text { Frequência das } \\
\text { palavras principais }\end{array}$ & $\begin{array}{c}\text { Queda de } \\
\text { frequência (\%) }\end{array}$ \\
\hline Núcleo central & Sofrimento & 9 & 9 & 0 \\
& Hospital & 8 & 7 & 12,5 \\
& Prevenção & 7 & 6 & 14,3 \\
& Remédio & 5 & 4 & 20 \\
& Alimentação & 10 & 7 & 30 \\
& Cura & 5 & 3 & 40 \\
& Estresse & 5 & 3 & 40 \\
& Dor & 12 & 7 & 41,7 \\
& Tristeza & 9 & 5 & 44,4 \\
& Câncer & 6 & 3 & 50 \\
& Morte & 10 & 5 & 50 \\
& Cuidado & 8 & 3 & 62,5 \\
& Mal estar & 6 & 2 & 66,7 \\
& Médico & 5 & 1 & 80 \\
\hline
\end{tabular}


da acima de dois salários mínimos, e envolvidos com o movimento social da saúde a um tempo significativo (seis a dez anos).

A participação majoritariamente masculina nos movimentos sociais pode demonstrar que ainda prevalece à atuação política circunscrita ao sexo masculino, herdada da nossa cultura patriarcal. Neste sentido, verifica-se que, apesar do crescimento dos movimentos sociais de mulheres para a defesa de diversas causas, as conquistas feitas pelas mulheres durante o século 19 , como o direito a voto, direito a um salário e direito a participar de processos sindicais e comunitários, considerados como os primeiros passos frente à agenda feminista da metade do século XX rumo à igualdade de direitos, tanto na vida privada como na pública, ainda não podem ser generalizadas para todas as mulheres ${ }^{21}$.

Em relação à participação de sujeitos jovens, de maior escolaridade, pode se aventar a hipótese de que, estes possuem maior compreensão de seus direitos e deveres e, por isso, mobilizam-se para alcançar maior domínio de sua cidadania. Além disso, atualmente as inovações tecnológicas, especialmente as redes digitais e sociais têm estimulado os jovens sem trajetória de participação política em partidos e sindicatos a se interessarem por questões relacionadas às demandas identitárias e grupais, focadas em problemas do cotidiano como emprego, mobilidade urbana, educação, saúde, moradia e terra para viver e plantar $^{10}$.

É interessante notar, também, que apesar da maioria dos sujeitos ser usuária do SUS, alguns participantes de movimentos sociais utilizam o plano de saúde privado. Os planos privados de saúde constituem-se complexo problema para o SUS, que se propõe a ser um sistema universal numa perspectiva de reduzir os altos indicadores de saúde, associados inclusive ao medidor de pobreza ${ }^{22}$.

A rarefação dos debates sobre as conexões entre o público e o privado, e a contraditória participação das entidades sindicais nas arenas de negociação sobre a atenção à saúde reforçam as teses de que a saúde pública deve ser destinada a quem realmente não pode $\operatorname{pagar}^{20}$. É, pois, necessário debater os conteúdos e a direcionalidade das políticas de regulação para recolocar a centralidade do sistema universal de saúde ${ }^{22}$.

Os movimentos sociais constituem importantes atores para participar desses debates, na medida em que se caracterizam por um forte traço reivindicativo na luta por conquistas na efetivação de demandas sociais, vale dizer, dos direi- tos sociais que incluem o acesso à saúde pública de qualidade.

A preocupação com o processo saúde-doença, objeto das representações sociais de integrantes de movimentos sociais deste estudo, é tema de forte impacto na vida das pessoas ${ }^{19}$. Faz parte de conversações cotidianas, de matérias dos meios de comunicação de massa, foco dos programas de pesquisa científica e pauta das ações governamentais, a saúde e a doença, remetem, ao mesmo tempo, à vida e à morte, à força e à fragilidade do $\operatorname{ser}^{22}$. Como fenômenos biológicos individuais, são interpretados a partir de um modelo de referência cultural, o que os torna 'imediatamente sociais', portanto, verdadeiros objetos de representações sociais ${ }^{22}$.

Verifica-se que a "qualidade de vida" faz parte do núcleo central das representações sociais. Esta representação encontra ancoragem na Declaração de Direitos Humanos que trata do direito ao bem-estar e à qualidade de vida, que é legitimada pela Constituição Federal de 1988, que em seu artigo 196 afirma a saúde ser um direito de todos e dever do Estado ${ }^{6,23,24}$.

Todavia, há que se ressaltar que o termo qualidade de vida se apresenta polissêmico, e admite diferentes formas de abordagens. No campo da saúde coletiva a qualidade de vida se expressa em perspectiva ampla em sua relação com a compreensão das necessidades humanas fundamentais, materiais e espirituais, e com a incorporação da perspectiva da promoção da saúde ${ }^{23-25}$. Outra forma de perceber a qualidade de vida centra-se na compreensão do ser humano viver sem doenças ou com capacidade para superar as dificuldades dos estados ou condições de morbidade ${ }^{25,26}$.

Identificou-se também no sistema periférico mais próximo do núcleo central das representações sociais a saúde relacionada com a "alimentação" adequada. A alimentação também está presente no sistema periférico próximo das representações sociais de doença, porque possivelmente é entendida como elemento cuja falta ou má qualidade acarreta desequilíbrio orgânico, psíquico e social. Os elementos periféricos possuem as funções de concretização, ancoragem e regulação, propiciando a mobilidade, evolução e defesa da representação social ${ }^{1,17}$. São esquemas de funcionamento da representação social, que podem contribuir para prescrever comportamentos, sobretudo, permitir a modulação das representações sociais e das condutas, corroborando para proteger, assim, o núcleo central das representações ${ }^{1,17}$.

Nesta perspectiva, os movimentos sociais vocalizam o acesso ao alimento como condição 
para ter saúde, portanto, para a garantia da vida. Cabe ressaltar que a participação das mulheres em movimentos e organizações no campo da organização alimentar no Brasil tem sido relevante, sobretudo colocando em destaque a luta pela eliminação da miséria e da fome. Nesta luta também estão em cena não apenas os Sem Terra, mas também pequenos agricultores para implementarem a produção no campo $^{10}$. Todos esses movimentos sociais convergem para a centralidade do acesso ao alimento, o que pode aumentar as pressões para a garantia de políticas públicas.

Como resultado dos esforços desses movimentos, a questão da segurança alimentar e nutricional está colocada na agenda política desde o final da década de 80 e, no início dos anos 90, por meio da Campanha "Ação da Cidadania contra a Fome, a Miséria e pela Vida”, que enfatizou para a sociedade e o Estado a necessidade de políticas para eliminar a miséria e a fome de milhões de brasileiros $^{27}$. Essa problemática ganhou mais espaço nas políticas públicas após o ano 2000, com a criação do "Programa Fome Zero", que teve repercussões positivas, mas que ainda requer atenção, sobretudo, à qualidade da alimentação que promova a saúde ${ }^{27}$.

Observou-se também, no sistema periférico mais próximo do núcleo central das representações sociais da saúde, a importância dada ao atendimento recebido, aos cuidados médico, ao bem-estar e à paz. E a saúde como um direito (com a provisão de todos os tipos de serviços públicos de saúde necessários), garantida por meio de políticas públicas.

A garantia desse direito tem sido problemática, por diversos motivos, mas, sobretudo pela dificuldade de acesso aos serviços de saúde necessários à integralidade da atenção, que são acentuados pelas desigualdades regionais. Segundo Dallari et al. ${ }^{23}$, o Estado deve ser constantemente pressionado pela sociedade civil politicamente constituída, para que ela tenha seus direitos sociais garantidos. Especialmente porque o Estado atual sofre grandes influências da racionalidade macroeconômica, que corrobora para modificar a concepção de direito à saúde, que fica concebida apenas como um dos pilares do direito do consumidor, ou seja, restrita à oferta de alguns serviços básicos de saúde.

Verificou-se ainda que os aspectos psicossociais, como amor e alegria, de suma importância para manutenção da saúde, encontram-se no sistema periférico distante das representações. Esses dados indicam que o modelo funcionalista de saúde, que reduz a sua compreensão ao desequi- líbrio orgânico está sendo ultrapassado por um modelo que abarque as dimensões psicossociais. Nessa lógica de compreensão, pode-se modificar o sistema de cuidado requerido que é o hospital, com o apoio dos medicamentos que se encontram no sistema periférico das representações sociais da saúde.

É interessante destacar que a palavra "trabalho" foi mencionada somente no sistema periférico distante, mas que é elemento essencial na vida dos sujeitos, sobretudo, trazido de modo mais enfático como direito de bem viver pelos movimentos de trabalhadores. Este dado demonstra que o processo saúde doença não é compreendido como processo social que atribui à esfera da reprodução social o processo de desgaste do trabalhador ${ }^{28}$

Acerca da representação social de doença, encontrou-se a relação mais significativa com "sofrimento", que se localiza no provável núcleo central. Já no sistema periférico próximo foram evidenciados os aspectos negativos provocados pela doença, como mal-estar, a dor, a tristeza, inclusive a morte. Além do sistema de cuidados, os movimentos sociais da saúde, novamente, destacaram a importância do médico, do remédio e do hospital.

Chama atenção a representação da prevenção que foi trazida no contexto da doença, mais como resultado da falta de cuidado com a saúde, portanto, considerado de responsabilidade individual. Essa concepção de prevenção tende a culpabilizar as pessoas que não conseguem alcançar a saúde, porque descontextualiza as questões oriundas das determinações sociais ${ }^{4,5,29}$.

Ainda quanto à representação da doença, embora encontrado no sistema periférico distante, foi interessante notar que, além dos fatores desencadeados pelo cotidiano da vida moderna, como estresse, os sujeitos citaram o Câncer, uma enfermidade que sabidamente atualmente causa grande impacto individual e social, por ser vista como doença de difícil tratamento e até mesmo como sinônimo de morte certa. Algumas doenças, como o Câncer, firmam-se no imaginário coletivo corroborando para a formação de representações, que ocorrem por meio do apoio em conceitos, símbolos e estruturas interiorizadas na interpretação de fenômenos orgânicos, que são amplamente veiculados pelas mídias na contemporaneidade ${ }^{30}$.

É relevante apontar que é impossível dissociar as noções de saúde e doença, pois uma noção está sempre remetida à outra. Todavia, fazer equivaler a saúde e a doença a situações polares 
de uma mesma coisa, identificadas segundo mesma racionalidade, é muito limitante para a apropriada compreensão dessas duas construções discursivas e das práticas a elas relacionadas, quanto negar as estreitas relações que guardam uma com a outra na vida cotidiana ${ }^{31}$.

Nesta perspectiva, depreende-se que os movimentos sociais evidenciaram que as representações sociais do processo saúde doença demonstram avanços, sobretudo porque tem no seu núcleo central a qualidade de vida, mas coabitam no sistema periférico elementos que ampliam a noção de saúde e elementos que a reduzem aos fatores de riscos, que estão fortemente ancorados no modelo hegemônico. Estas representações podem levá-los a conceber a saúde como um bem a ser buscado incessantemente, por meio do acesso aos serviços de saúde e a procedimentos, e até mesmo, a buscar a mudança de comportamento de modo individual ${ }^{28}$.

Acrescenta-se que corroboram para reforçar essas representações as mídias, que frequentemente divulgam o hospital como o local onde se resolvem todos os problemas de saúde e promovem proteção contra as doenças ${ }^{20}$, sem destacar a importância dos outros níveis de atenção à saúde, especialmente os que abarcam as ações de promoção à saúde.

Essas representações revelam ainda que, apesar dos movimentos sociais apresentarem, aparentemente, um discurso de saúde abrangente, têm ainda dificuldade de materializá-lo nas discussões e proposições realizadas em arenas políticas. Podem contribuir para ocorrência de tal dissonância à cultura medicalizante na qual estão inseridos, bem como pela histórica relação estabelecida entre população e serviços de saúde, em que a demanda é usualmente dirigida a garantir acesso aos medicamentos, procedimentos especializados e atendimento médico em detrimento da implementação de ações de prevenção e promoção à saúde ${ }^{32}$.

Consta-se também que essas representações estão distanciadas da compreensão do processo saúde-doença como resultante do processo de produção, enquanto, uma formação social totalizante, coordenados por estruturas singulares e muito dinâmicas ${ }^{28}$. Nesta forma de compreensão, embora se reconheça que grande parte dos determinantes, relevantes componentes da qualidade de vida, esteja frequentemente situada fora do setor saúde, o sistema de saúde adota uma posição exclusivamente retórica ${ }^{22,28}$.

\section{Considerações Finais}

As representações sociais da saúde dos integrantes de movimentos sociais assinalam que estas avançaram, tendo a qualidade de vida como o seu núcleo central. Nesta perspectiva, os movimentos sociais juntamente com o conjunto da sociedade podem definir o seu padrão, para garantir a integralidade da atenção, mobilizar-se para conquistá-lo, sobretudo, por meio de políticas públicas e sociais, que induzam e norteiem o desenvolvimento humano, as liberdades individuais e coletivas, bem como as mudanças no modo, no estilo de vida e, principalmente, nas condições sociais $^{25,26}$.

Todavia, há que se considerar que no sistema periférico das representações sociais da saúde e da doença dos movimentos sociais estão presentes elementos que ampliam a noção de saúde, mas também elementos que a reduzem aos fatores de riscos, que são prevalentes, e que podem levar os movimentos sociais a reivindicarem por uma atenção à saúde baseada no modelo hegemônico.

Desta feita, urge que os movimentos sociais compreendam esse fenômeno, como processo social, que atribui à esfera da reprodução social a determinação dos processos de desgastes e adoecimentos ${ }^{28}$ para avançar na concepção do processo saúde-doença.

\section{Colaboradores}

HE Shimizu na concepção e desenho, análise e interpretação dos dados, da elaboração do artigo e revisão crítica do conteúdo intelectual, e aprovação final da versão a ser publicada do artigo; JR Silva participou da concepção e desenho, análise e interpretação dos dados, bem como coleta dos dados; LM Moura participou da coleta de dados, revisão crítica do conteúdo intelectual e aprovação final da versão a ser publicada do artigo. MM Odeh trabalhou na revisão crítica do conteúdo intelectual e aprovação final da versão a ser publicada do artigo, bem como da tradução do resumo para língua inglesa. XP Bermúdez trabalhou na revisão crítica do conteúdo intelectual e aprovação final da versão a ser publicada do artigo. 
Agradecimentos

Ao PIBIC/CNPq pela bolsa de JR Silva.

\section{Referências}

1. Abric JC. Central system, peripheral system: their functions and roles in the dynamic of social representations. Papers on Social Representations 1993; 2(1):75-78.

2. Paim JS. A reforma sanitária brasileira e o Sistema Único de Saúde: dialogando com hipóteses concorrentes. Physis 2008; 18(4):625-644.

3. Coelho IB. Democracia sem equidade: um balanço da reforma sanitária e dos dezenove anos de implantação do Sistema Único de Saúde no Brasil. Cien Saude Colet 2010; 15(1):171-183.

4. Buss PM. Uma introdução ao Conceito de Promoção da Saúde. In: Czeresnia D, Freitas CM, organizadores. Promoção da saúde: conceitos, reflexões, tendências. Rio de Janeiro: Fiocruz; 2003.

5. Buss PM, Carvalho AI. Desenvolvimento da promoção da saúde no Brasil nos últimos vinte anos (1988-2008). Cien Saude Colet 2009; 14(6):2305-2316.

6. Brasil. Lei $\mathrm{n}^{\circ} 8.080$, de 19 de setembro de 1990. Dispõe sobre as condições para promoção, proteção e recuperação da saúde, a organização e o funcionamento dos serviços correspondentes e dá outras providências. $\mathrm{Di}$ ário Oficial da União 1990; 20 set.

7. Tourraine A. Na fronteira dos movimentos sociais. Soc Estado 2006; 21(1):17-28.

8. Scherer-Warren I. Das mobilizações às redes de movimentos sociais. Soc Estado 2006; 21(1):109-130.

9. Goss KP, Prudêncio K. O conceito de movimentos sociais revisitado. Em Tese 2004; 2(1):75-91.

10. Gohn MG. Pluralidade da representação na América Latina. Soc Estado 2014; 29(1):73-90.

11. Cohn A. Estado e sociedade e as reconfigurações do direito à saúde. Cien Saude Colet 2003; 8(1):9-18.

12. Gohn MG. Abordagens teóricas no estudo dos movimentos sociais na América Latina. Cad CRH 2008; 21(54):439-455.

13. Gohn MG. Empoderamento e participação da comunidade em políticas sociais. Saúde Soc. 2004; 13(20):20 31.

14. Franco MLPB. Representações sociais, ideologia e desenvolvimento da consciência. Cadernos de Pesquisa 2004; 34(121):169-186

15. Moscovici S. Representações sociais: La Psychanalyse, son image, son public. Paris: PUF; 1961.

16. Bovina IB. Réprésentations sociales de la santé et de la maladie chez les jeunes Russes: force versus faiblesse. Textes sur lês réprésentations sociales 2006; 15(1):5.15.11.

17. Sá CP. Teoria das representações sociais: teoria e pesquisa do núcleo central. Temas em Psicol 1996; 3(1):1933.

18. Trindade ZA, Meandro MCS, Nascimento CRR, organizadores. Masculinidades e Práticas de Saúde. Vitória: GM; 2011.
19. Almeida MOA, Santos MFS. Representações sociais masculinas de saúde e doença. In: Trindade ZA, Meandro MCS, Nascimento CRR, organizadores. Masculinidades e práticas de saúde. Vitória: GM; 2011. p. 99-128.

20. Gomes AMT, De Oliveira DC, Sá CP. O Sistema Único de Saúde na representação social de usuários: uma análise de sua estrutura. Rev Bras Enferm 2011; 64(40):631638

21. Olaya E. La promesa de igualdad, en la democracia sigue siendo un debate para las mujeres. Rev Katálysis 2010; 13(1):59-65.

22. Santos NR. SUS, política pública de Estado: seu desenvolvimento instituído e instituinte e a busca de saída Cien Saude Colet 2013; 18(1):273-280.

23. Dallari SG, Adorno RCF, Faria MM, Shuqair NSMSAQ Trewikowski S. O direito à saúde na visão de um conselheiro municipal de saúde. Cad Saude Publica 1996 12(4):531-540.

24. Noronha JC, Soares LT. A política de saúde no Brasil nos anos 90. Cien Saude Colet 2001; 6(2):445-450.

25. Minayo MCS. Qualidade de vida e saúde como valor existencial. Cien Saude Colet 2013; 18(7):1868-1868.

26. Minayo MCS, Araújo HZM, Buss P. Qualidade de vida e saúde: um debate necessário. Cien Saude Colet 2000; 5(1):7-18.

27. Vieira VL, Gregório MJ, Cervato-Macuso AM, Graça APSR. Ações de alimentação e nutrição e sua interface com segurança alimentar e nutricional: uma comparação entre Brasil e Portugal. Saúde Soc 2013; 22(20):603607.

28. Dos Reis AM, Soares CB, Campos CMS. Processo saúde-doença: concepções do movimento estudantil da área da saúde. Saúde Soc. 2010; 19(2):347-357.

29. Lopes MSV, Saraiva KRO, Fernandes AFC, Ximenes LB Análise do conceito de promoção da saúde. Texto Contexto Enferm 2010; 19(3):461- 468.

30. Câmara AMCS, Melo VLC, Gomes MGP, Pena BC, Silva AP, Oliveira KM, Moraes APS, Coelho GR, Victorino LR. Percepção do processo saúde-doença: significados e valores da educação em saúde. Rev Bras Edu Med 2012; 36(1):40-50.

31. Ayres JRCM. Uma Concepção Hermenêutica de Saúde. Physis 2007; 17(1):43-62.

32. Paiva FS, Van Stralen CJ, Costa PHA. Participação social e saúde no Brasil: revisão sistemática sobre o tema. Cien Saude Colet 2014; 19(2):487-498.

Artigo apresentado em 02/07/2014

Aprovado em 07/03/2015

Versão final apresentada em 09/03/2015 